\title{
Garcilaso de la Vega: maestro de la Historia
}

\section{Garcilaso de la Vega: teacher of History}

RICHARD L. KAGAN

Universidad Johns Hopkins

kagan@jhu.edu

\section{RESUMEN}

Este artículo aborda la figura de Garcilaso de la Vega como historiador y la influencia que ejerció en la práctica historiográfica de sus contemporáneos; concretamente, del cronista general de las Indias, Pedro de Valencia. De este modo, se recogerán los requisitos fundamentales que Garcilaso consideraba al momento de escribir una historia: procurar la verdad, poseer fuentes fidedignas y transmitir la voz de aquellos que nacieron en el lugar del que se habla. Estas guías, en resonancia con cálculos politicos y personales, provocarían que, eventualmente, Valencia se abstenga de culminar su tratado de historia de conquista de Chile. Palabras clave: Garcilaso, Pedro de Valencia, Historia, Chile, Historiografia

\section{ABSTRACT}

This article addresses the figure of Garcilaso de la Vega as a historian and the influence he exerted over the historiographic writing of his contemporaries, concretely the one of the general chronicler of the Indies, Pedro de Valencia. Thereby, this study will discuss the principal requirements Garcilaso considered when writing history: to tell the truth, to possess reliable sources and to transmit the voices of those who were born in the place one is writing about. These guides, in resonance with personal and political calculations, would eventually provoke Valencia to refrain himself from finishing his investigation of the history of the conquest of Chile.

Keywords: Garcilaso, Pedro de Valencia, History, Chile, Historiography 


\begin{abstract}
Por mandado del Real Consejo de Castilla, he visto un libro que se intitula la segunda parte de los Comentarios Reales, escrito por el Inca Garcilaso de la Vega, repartido en ocho libros, y no hallo en él cosa contra la fe ni buenas costumbres. Paréceme muy digno de que se dé licencia para que se imprima, porque la historia es muy útil y gustosa, por los ejemplos de prudencia y extrańeza y variedad de los sucesos, y está tratada con claridad y apacible estilo, y principalmente con el celo de verdad y desapasionada intención, y que muestra haberse tomado de vistas o de ciertas y diligentes relaciones. En Madrid, 6 de enero $1614 .{ }^{1}$
\end{abstract}

Con este juicio, Pedro de Valencia autorizó la publicación de la segunda parte de los Comentarios Reales del Inca Garcilaso de la Vega, un libro que, después de un retraso de varios años, llegó a la imprenta y salió a la luz en 1617 . Se ha escrito mucho sobre esta obra junto con su autor; este artículo no pretende añadir novedades a dicha literatura tan abundante. Pero ¿quién era Pedro de Valencia? ¿Cómo llegó a la posición de tener el poder de autorizar o, en algunos casos, no autorizar la impresión de libros de historia? ¿Tenía alguna relación o amistad con Garcilaso? Y, finalmente, aparte de lo que escribió sobre el libro en el documento citado, ¿tenía Valencia otras ideas sobre la importancia de Garcilaso o su libro? Estos son algunos de los temas abordados en las siguientes páginas.

\title{
PEDRO DE VALENCIA
}

Hijo de un abogado de posible descendencia de sangre conversa, nació en 1555 en Zafra, un pueblo extremeńo ubicado unos 130 kilómetros al norte de Sevilla y que albergaba el palacio de su señor, el duque de Feria, uno de los nobles más importantes en la España moderna. Valencia pasó sus primeros años en Zafra antes de trasladarse a Córdoba con su familia en torno de 1570, donde estudió gramática latina, algo de teología y artes liberales en el recién establecido colegio de los jesuitas. En aquel momento, Garcilaso había dejado Perú para radicar en España en 1560

${ }^{1}$ Garcilaso de la Vega 1617. 
y residía en el pueblo de Montilla, muy cerca de Córdoba, pero no hay prueba de que tuviera contacto con la familia de Valencia o, por lo menos en aquel momento, con los jesuitas cordobeses. Sea lo que fuere, el joven Valencia pronto dejó Córdoba por Salamanca, donde se matriculó en la facultad de derecho de su universidad. No obstante, el derecho no le interesaba mucho y, aunque al final obtuvo un título de bachiller en leyes, gastaba la mayor parte de su tiempo estudiando las letras clásicas y humanísticas, aparte de aprender griego y hebreo. ${ }^{2}$

Al dejar la universidad, volvió a Zafra, donde, además de servir como bibliotecario del conde de Feria, se dedicó a escribir varios estudios de carácter humanístico y filosófico junto con una serie de tratados y discursos dedicados a varios temas de actualidad, tanto económicos como sociales. Uno de estos trató sobre los impuestos que los labradores en los alrededores de Zafra tenían que pagar — demasiados altos, a su perecer-; otro, sobre la corrupción de los recaudadores, es decir, los que estaban encargados de cobrar dichos impuestos; en otro argumentaba que había que reducirlos de acuerdo con la inflación; e incluso volcó su atención en el elevado costo del trigo y del pan, y de la necesidad por parte de la monarquía de reducir la pobreza. El más famoso de sus tratados es el dedicado a los moriscos, los musulmanes convertidos al cristianismo, que representaban una minoría importante en varias regiones españolas. A principios del siglo XVII, existía una corriente de opinión en favor la expulsión de los moriscos del reino, algo que ocurrió unos pocos años después, pero que fue una medida a la que Valencia se opuso. En su tratado, recomendó la necesidad de tener paciencia, brindar instrucción para los moriscos en la doctrina religiosa, y, de modo más radical, fomentar la asimilación a través de matrimonios entre moriscos y cristianos viejos. En otro tratado importante, escrito en 1610, Valencia demostró su tolerancia por la brujería y la necesidad de tratarla con un espíritu razonable y sentido común. También es importante reconocer que en este tratado y todos los otros que escribieron, Valencia expresaba sus opiniones en una manera abierta, franca, sincera y sin disimulo. ${ }^{3}$

2 Para la biografía de Valencia, véase Gómez Canseco 1983 y Valencia 1993-2016.

3 Valencia 1993-2016; Magnier 2010. 
Ante estos asuntos tan puntuales, Valencia nunca demostró ningún interés en la escritura de la historia, sea la de España o de las Indias. Por lo tanto, es algo sorprendente que, en 1605, el rey Felipe III lo nombrara cronista general de las Indias, un puesto que implicaba diferentes responsabilidades. ${ }^{4}$ Una de estas era la censura de varias clases de libros para evitar la difusión de su posible contenido herético y aprobar los adecuados para la imprenta. Aparte de la segunda parte de los Comentarios de Garcilaso, otros libros de historia que Valencia aprobó incluyeron la Historia de la Conquista de las Islas Molucas de Bartolomé Leonardo de Argensola (1609) y la Monarquía Indiana de fray Juan de Torquemada (1615), una historia monumental que interpretó la conquista de Nueva España como un acto providencial que liberó a los indígenas de la servidumbre del diablo y que les permitió conocer la verdadera religión. También en 1616, Valencia censuró, otra vez positivamente, la Historia General del Perú por fray Martín de Murúa. Su informe es breve, pero recomendó que se diese a este libro la licencia para la imprenta porque «no tiene cosa contra la fe ni las buenas costumbres i ayudaba mucho al cumplimiento de la historia del Perú, porque con mucha diligencia a descubierto i trata muchas cosas de las antigüedades del aquel reino i del govierno i descripción grandeza y maravillas naturales dél». ${ }^{5}$ En otras palabras, consideró la obra como complemento de la de Garcilaso, pero en este caso, y como es bien conocido, la impresión de esta obra tan importante se dilató hasta el siglo XX.

Al mismo tiempo, es importante reconocer que Valencia no era un incauto con respecto a las censuras de los manuscritos que llegaron a su despacho. Hubo obras cuya publicación no aprobó, entre ellas, la traducción castellana de Storia de la guerre de la Germania inferior (1614), una historia de la rebelión de los holandeses contra Felipe II. Obra del historiador italiano Girolamo Franchi de Conestaggio, Valencia la consideró poco más que una «invectiva contra su alteza» y que defendía «la causa en favor de los flamencos i condenar al Rey i toda la nación española». ${ }^{6}$

\footnotetext{
${ }^{4}$ Para este nombramiento, véanse Paniagua Pérez 1996; Kagan 2010 y 2017.

5 Murúa 1962-1964.

6 Valencia 1993-2016, V: 6.
} 
Aparte de la censura de los libros, la principal responsabilidad del nuevo cronista era la redacción o, mejor dicho, la continuación de la historia general de las Indias, específicamente la parte relativa a la conquista de Chile, un conflicto que estaba todavía en curso a principios del siglo XVII. El encargo de escribir aquella había sido previamente dado al cronista mayor de las Indias Antonio de Herrera y Tordesillas, pero por una serie de razones, entre ellas una guerrilla entre varias facciones en la corte real, el rey, apoyado por el Consejo de las Indias, decidió transferir este encargo a Valencia. ${ }^{7}$

La tarea de escribir la historia de Chile fue tomada seriamente por Valencia, quien empezó sus investigaciones en torno a 1609. Este año, por ejemplo, solicitó y recibió una licencia especial para realizar una visita al archivo real de Simancas, el depósito en aquella época de todos los documentos de carácter oficial perteneciente a la administración de las Indias. ${ }^{8}$ La oportunidad de consultar estos documentos representó un extraordinario privilegio. Los fondos de aquel archivo habían sido clasificados como arcana imperii, secretos de Estado, y casi nadie, salvo los archiveros reales, tenía el derecho de estar en Simancas sin licencia especial del rey. Al mismo tiempo, Valencia, como cronista oficial de las Indias, tenía la oportunidad de consultar materiales relevantes a la guerra chilena guardados en el dicho "archivillo» del propio Consejo de las Indias, un depósito que contenía documentos más recientes que todavía no habían sido enviados a Simancas junto con varios manuscritos, entre ellos, el de la Historia General de las Indias de Bartolomé de las Casas. ${ }^{9}$ Así, en una carta dirigida al presidente del Consejo de las Indias en enero de 1616, podía admitir que «se me an entregado por vuestro mandado muchos papeles relaciones i cartas de los virreyes del Perú i de los governadores de Chile, de que he copiado i sacado en relación todo lo perteneciente a la parte de la historia que me está encargada,

7 Kagan 2010: 275-279.

${ }^{8}$ Consulta del Comendador Mayor de León sobre la conveniencia de autorizar al cronista Pedro de Valencia el acceso a la documentación de Simancas, Archivo General de Simancas, Estado, leg. 1494; sin foliar.

9 Sobre este "archivillo», véase Brendetke 2016. 
particularmente desde el año de $1598 » .{ }^{10}$ Además, utilizó otras fuentes, entre ellas, testimonios de varias personas que habían estado en Chile. Antes de entrar en detalle sobre estas entrevistas, es importante señalar el estado de Chile a principios del siglo XVII y, por lo tanto, el carácter de la historia que Valencia tenía la responsabilidad de escribir.

\section{CHILE}

Merece la pena recordar que la situación de Chile en aquella época, es decir, a finales del siglo XVI y principios del siguiente, no era el de un territorio bajo control español. Era precisamente lo contrario a pesar de los esfuerzos de varios escritores como Alonso de Ercilla y Pedro de Ońa por describirlo en mejores tonos. En su famosa obra, La Araucana (1569, 1578 y 1589), Ercilla hizo todo lo posible por transformar la guerra entre los españoles y los indios mapuche en una épica heroica, la equivalente española de la guerra troyana. En cuanto el Arauco Domado (1596) —otra historia escrita en verso-, su propósito principal era glorificar las hazañas de García Hurtado de Mendoza como gobernador militar en Chile entre 1556 y 1561 . No es necesario detenerse en los detalles, pero, a principios del siglo XVII, la «pacificación» de aquel reino iba mal, sobre todo en las regiones localizadas al sur del rio Biobío y del puerto de Concepción. Según varios testigos oculares, entre ellos el jesuita Luis de Valdivia, aquel conflicto era una "guerra de maloca» $y$ los soldados españoles, unos maloqueros o aventureros, menos ocupados en pacificar la zona, fundar pueblos, cultivar la tierra y promover la paz, seguridad y la evangelización, que hacer todo lo posible por sacar "piezas», esto es, capturar a los jóvenes y las mujeres para esclavizarlos, guardando unos para el servicio personal y enviando otros al Perú para ser puestos en venta en el mercado de esclavos en el puerto del Callao. Valdivia calificó el ejército español en Chile como un "fuego abrasador», compuesto de varios tipos de soldados: «[uno que] desfloraba la india

${ }^{10}$ Relación de Pedro de Valencia, 13 de enero de 1616, Archivo General de Indias [en adelante AGI], Indiferente General, leg. 755. 
donzella, otro adulteraba la casada, otro hurtaba a los niños, y los llevaba a vender fuera de allí, diziendo que eran esclavos». ${ }^{11}$

Al largo plazo, esta guerra de malón produjo menos paz que resistencia por parte de varios grupos de indios, y, en 1598, catalizó una gran sublevación que resultó en el abandono de varias ciudades de la zona (Imperial, Puerto de Valencia), junto con la muerte de gobernador del reino, Martín García de Loyola. Su sucesor respondió con una guerra ofensiva y más brutal, descrita como una de «fuego y sangre» que duraría varios años. El virrey del Perú, el conde de Monterrey, reaccionó en una manera diferente. Encargó el padre Valdivia organizar una visita a Chile con la esperanza de proponer las políticas necesarias para acabar la guerra y establecer una vía hacia a la pacificación. Al final de esta visita, Valdivia recomendó un giro de táctica, una que cambiara la guerra ofensiva por una más defensiva y también una que prohibiera la esclavización de los indígenas. Sus recomendaciones llegaron primero a Lima, donde fueron aprobadas por el virrey, antes de llegar a Madrid en 1605, casi al mismo momento que Valencia salía de su pueblo natal de Zafra camino a la Villa para asumir el cargo de cronista.

Las recomendaciones de Valdivia provocaron un debate intenso en la corte. Allí surgieron dos partidos: el de guerra defensiva y la prohibición de la esclavitud de los indios, y el de la guerra a fuego y sangre. En 1608 , ambos partidos llegaron a un compromiso en la forma de una real cédula que solo permitió la esclavitud de los indios que habían negado obediencia a la iglesia. ${ }^{12}$ Sin embargo, en la práctica, la situación en Chile quedó igual. La guerra de maloca continuaba y Alonso González de Nájera, un capitán que había estado en el frente y que llegó a la corte en medio de este debate, manifestó que «víboras» son «nuestros soldados españoles para los indios de Chile», y la guerra en aquel reino equivalía a «una caza y montería de fieras». ${ }^{13}$

En torno en 1609, Valdivia llegó a Madrid y renovó el debate cuando distribuyó un memorial impreso que incluía un catálogo de los aspectos

\footnotetext{
${ }^{11}$ Valdivia 1610: 4.

12 Véase Jara 1971; Díaz Blanco 2010.

${ }^{13}$ González de Nájera 1866: 452.
} 
más lamentables de la guerra ofensiva, arguyendo que era una receta para más guerra y resistencia por parte de los indios. Valdivia permaneció en la corte casi dos años, negociando con los ministros y tratando de lograr su apoyo. Entre tanto, los gobernadores chilenos hacían poco por cambiar el carácter de la guerra chilena, ya que la maloca seguía, y también la crisis.

Podemos imaginar que Valencia, ya embarcado en la realización de su historia de Chile, realizaba entrevistas con González de Nájera junto con Valdivia, pero hasta el momento estas entrevistas son difíciles de comprobar. Algunos años más tarde, Valencia entrevistó a varios soldados, veteranos de aquella guerra que habían regresado a España, entre ellos a Pedro Cortés de Monroy, un maestre del campo. Valencia escribió que en 1613 «he tomado relación por escrito de boca del Maestre del Campo, Pedro Cortés, de cerca de sesenta años de las cosas sucedidas en la provincia u guerra del reino de Chile». ${ }^{14}$

Armado con esta información, junto con el material que había reunido de varios archivos, Valencia parece que empezó de escribir la historia de Chile. Pero ¿cuándo? No se conoce la fecha precisa. Lo que es cierto es que no tardaría mucho en tener reservas sobre el valor de su participación en el proyecto. La cronología no es totalmente clara, pero parece que sus reservas empezaban alrededor de 1614, el mismo año en que leyó el manuscrito de la segunda parte de Comentarios Reales.

\section{LAS LECCIONES DEL INCA GARCILASO}

Se desconoce lo que Valencia aprendió de su lectura de este manuscrito, pero parece que el texto del Inca, aparte de proveerle con nueva información en relación de la historia peruana, le ofreció varias lecciones importantes de carácter historiográfico junto con otras directamente relevantes a la historia de Chile que había empezado a redactar. Es probable que estas lecciones fueran tres: escribir la verdad, poseer fuentes fidedignas y contar con testimonios de los hijos de la tierra.

${ }^{14}$ Memorial de Pedro de Valencia, 13 de enero de 1616, AGI, Indiferente General. leg. 1443. 
La primera lección, trabajar con la verdad, consistió — citaba Garcilaso- en que «la historia manda y obliga [a los historiadores] a escribir verdad, so pena de ser burladores de todo el mundo, y por ende infames». ${ }^{15}$ Con esta observación, Garcilaso hacía referencia a Cicerón, particularmente a su obra De Oratore, donde el famoso autor romano había ofrecido consejos importantes sobre la disciplina de la historia y la manera de escribirla. Cicerón sentenció que la historia debiera ser lux veritas, la lámpara de la verdad, una idea que los tratadistas renacentistas de la historia, entre ellos el español Luis Cabrera de Córdoba, contemporáneo tanto de Garcilaso como de Valencia, adoptaron. Autor de La historia, y como escribirla, Cabrera consideró la historia como la narración de lo verdadero o lo que otros tratadistas habían denominado la "historia legítima y perfecta». ${ }^{16}$

Es necesario entender que este concepto —el de la historia perfectaera un ideal, algo que, en la práctica, era casi imposible de realizar. En su Historia, Garcilaso aspiraba a escribir solo la verdad, pero hay que matizar lo que entendía como la «verdad». Es notorio que, junto la mayoría de los historiadores de su época, su interpretación de la verdad no le prevenía de intentar utilizar su historia para mejorar o, por lo menos, enaltecer la imagen y la reputación de varias personalidades, entre ellas la de su padre junto con la de Cristóbal Vaca de Castro, el gobernador que había sido criticado - e incluso juzgado por un tribunal — por algunas supuestas faltas durante su estancia en el Perú. Así, parece que la verdad histórica para Garcilaso fue un concepto flexible, sujeto a posible manipulación. Por otro lado, y frente a otros historiadores — entre ellos, Antonio de Herrera y Tordesillas, quien en unas ocasiones alteró el contenido de sus narraciones a cambio de dádivas que había activamente solicitado-, Garcilaso fue un paradigma de honestidad. De este modo, era fiel a lo que el escritor griego del segundo siglo, Luciano de Samosata, aconsejó en su tratado Cómo se debe escribir la historia. Precisamente, Garcilaso poseía en su biblioteca un libro de Luciano, quien seńalaba que el historiador

${ }^{15}$ Garcilaso 1617, II: lib. I, cap. XVIII.

${ }^{16}$ Cabrera de Córdoba 1948: 28. 
tenía que utilizar el elogio como la censura con cautela y consideración, libre de calumnia y apoyado por pruebas. De lo contrario, advirtió, «es Vd que sufrirá la censura, como el historiador Theopompus, el que hacía un negocio de impugnando otros con el espíritu maligno, y actuándose como un acusador en vez de un cronista». ${ }^{17}$

En cuanto a Valencia, se conoce que, como experto humanista, conocía las obras de Luciano y que su idea de la historia como disciplina se aproximaba a la de Cicerón. Así, entendía que el historiador tenía la responsabilidad de reconstruir el pasado en una manera verídica. Esta idea se manifestó en sus críticas del historiador contemporáneo italiano, el cardenal Cesare Baronio, autor de los famosos Anales Ecclesiastici, obra que, entre otras cosas, cuestionó la veracidad del culto, tan importante para España, del apóstol Santiago. En política, Baronio fue contrario al dominio espańol en Nápoles, una postura que llevó a Valencia a describir al cardenal como «opuesto a España». Incluso peor desde su punto de vista, Baronio era un escritor que había permitido que su pensamiento político influyera en la manera de escribir la historia. De tal forma, Valencia consideró que Baronio había redactado los Anales con una «voluntad apasionada» junto con cierto espíritu de «malignidad». Por tal motivo, juzgó los Anales de Baronio menos como una obra de Historia y más como una «burla» del tipo que se encuentra en las comedias. ${ }^{18} \mathrm{Se}$ sigue que Valencia, al emprender la composición de su historia de Chile, hizo todo lo posible evitar por un juicio parecido. Siguiendo el ejemplo de Garcilaso, pretendía escribir la verdad y solo la verdad.

Respecto a la segunda lección, Valencia reconoció la importancia del testimonio directo y personal, es decir, las fuentes fidedignas. En muchos sentidos, los Comentarios reales del Inca constituyeron un esfuerzo por su parte de corregir las historias ya existentes del Perú, entre ellas, la Historia de las Indias, obra del capellán de Hernando Cortés, Francisco López de Gómara, e impresa por primera vez en 1554. El historiador Raúl Porras Barrenechea, al encontrar el ejemplar de este libro que Garcilaso tuvo en

\footnotetext{
${ }^{17}$ Luciano 1959: 71.

${ }^{18}$ Valencia 1993-2016, IV: 217.
} 
su propia biblioteca, descubrió que el Inca, al leerlo, reaccionaba fuertemente a las afirmaciones que consideraba erróneas junto con las que contradecían sus propias experiencias y observaciones de cuando residió en Perú y también de lo que había aprendido de la historia de los incas a través de la tradición oral de sus padres y otros parientes. ${ }^{19}$ Así, salpicó las márgenes del aquel libro con frases como «es falso», "es mentira», "miente» o «miente en todo ésto». ${ }^{20}$ En cierto momento, estuvo tan enfadado que escribió «que merecía que quemasen el libro y a quien lo escribió». El tono de estas críticas es deducible del texto de los Comentarios; sin embargo, al repasar el manuscrito inédito del Inca, Valencia todavía pudo encontrar frases tales como "escribía [es decir Gomara] lejos del lugar de los acontecimientos y obtuvo su información de personas [...] cuyos informes de las cosas habían ocurridos fueron erróneas». ${ }^{21}$

La importancia para el historiador de ser un testigo ocular de los acontecimientos, cuya historia pretendía redactar, fue otra de las reglas fundamentales de la historia humanística. ${ }^{22}$ Luis Cabrera de Córdoba, por ejemplo, subrayó que el historiador tenía la responsabilidad de "valerse de diversas y variables informaciones a partir de las cuales debiera argumentar sobre probables en la diversidad de los hechos que le refieren, para sacar en limpio la fineza de la verdad y establecer lo que más verdadero o verisímil le pareciere». ${ }^{23}$

Esta misma lección Garcilaso habría aprendido de su lectura de varios historiadores, entre ellos Polibio, cuyos libros figuran en la biblioteca del Inca, y quien había aconsejado que «los ojos son testigos más precisos que las orejas». ${ }^{24} \mathrm{Al}$ mismo tiempo, es posible que el Inca aprendiera la misma lección en su lectura de otro libro en su biblioteca: la Historia General y Natural de las Indias de Gonzalo Fernández de Oviedo. Como es bien sabido, Oviedo nunca vacilaba en criticar a Pedro Mártir de

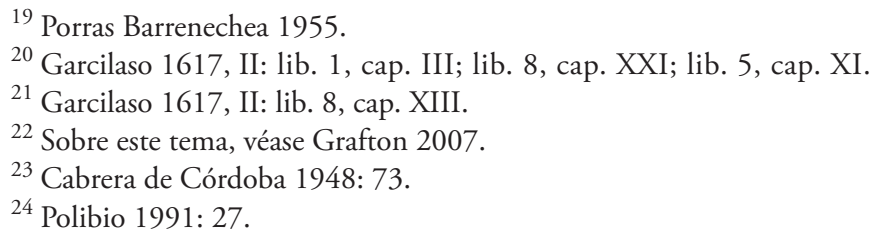


Anglería, autor del primer relato histórico del Nuevo Mundo a pesar del hecho de que nunca había atravesado el Atlántico. Por esta razón, Oviedo criticó el valor de su obra, insistiendo que estuvo llena de errores y falsedades de varios tipos. Pero más que nada, la importancia de fuentes fidedignas era una lección que el Inca habría aprendido, sobre la marcha, en su lectura de Gómara, un autor cuya relación de la historia peruana le parecía mal informada.

Se sigue que Garcilaso - y esto es evidente en sus Comentarios realesintentó recordar a los lectores de su obra que su información era de primera mano, el producto directo de lo que había visto cuando vivía en Perú y, con respecto a la historia de los Incas, lo que sus padres y otros parientes le habían contado. Esta lección —la importancia de las fuentes fidedignas y, si no, personales - fue otra que Valencia extrajo de su lectura del Inca.

Finalmente, sobre la tercera lección, y con respeto a la historia de la conquista de Chile, hacía el final de segunda parte de los Comentarios reales, Garcilaso expresó su interés en tener una historia completa de lo que había ocurrido allí. Al mismo tiempo, enfatizó la necesidad de contar con una historia verdadera y escrita por "uno de sus propios hijos». ${ }^{25}$ No definió lo que entendía por esta frase, pero podemos imaginar que se refería a un autor mestizo, alguien de origen parecido al suyo, o a un español de origen criollo, junto con una persona que conociera bien el territorio, los personajes principales y con experiencia directa y personal con aquella guerra.

¿Como reaccionó Pedro de Valencia a esta recomendación? A lo largo del manuscrito de los Comentarios Reales, había encontrado la manera en que Garcilaso criticó a escritores como López de Gómara, que había escrito la historia de Perú sin pisar tierra peruana ni americana. También, habría tomado en cuenta el número de veces en que Garcilaso insistía que fundaba gran parte de su obra en su propia memoria y en la observación directa, es decir, el testimonio visual, o lo que conocemos como la autobiografía.

${ }^{25}$ Garcilaso 1617, II: lib. 8, cap. XIII. 


\section{VALENCIA Y LA AUTOCENSURA}

Es difícil restar importancia a estas tres lecciones para Valencia. Recapitulando: la necesidad de escribir una historia verídica, la importancia de testimonios fidedignas y ser «uno de sus propios hijos» del lugar del que se escribe. Todos fueron consejos que Valencia se tomó a pecho, tanto que pronto empezó de tener unas dudas importantes sobre su capacidad y cualificación para escribir la historia de Chile en la que ya se había embarcado.

Aquí es importante recordar que aparte de ser cronista, Valencia era padre, con una esposa y cuatro hijos que mantener. En consecuencia, tenía otras obligaciones; y como un hombre falto de otros ingresos, le era necesario el sueldo que el cargo de cronista le traía. El puesto le demandaba presentar al Consejo de Indias cada mes de diciembre una relación de todo lo que había escrito a lo largo del año precedente. De esta forma, el dilema de Valencia era el de escribir o no escribir, de comer o no comer. Al fin, y para escapar de esta situación, decidió redactar varias peticiones al Consejo de las Indias en que trató de excusar la dilación en la entrega de la relación de las partes de la historia que llevaba escritas. Explicó que se había ido a Simancas, donde consultó muchos papeles en el archivillo del Consejo y realizado varias entrevistas con veteranos de la guerra chilena. Con estas peticiones, Valencia trató de convencer al Consejo que merecía el pago de su sueldo de cronista, pero sus miembros requerían más e insistían que les debía mostrar lo que había escrito de la historia.

En este momento, parece que Valencia, reflejando una vez más sobre lo que había aprendido de su lectura de Garcilaso, vaciló de nuevo y ofreció más excusas por su decisión de no escribir, algo que se puede denominar un acto de autocensura. Es plausible que casi todos los historiadores, en un momento u otro a lo largo de su carrera, han tenido dudas sobre su propia capacidad o cualificaciones de continuar un proyecto todavía en marcha o uno que ya iba mal. Por lo tanto, es posible mostrar una simpatía para Valencia, un excelente humanista, uno que en sus varios tratados siempre estaba preparado de escribir verdades, pero uno, que, al enfrentar la realidad de escribir la historia tan conflictiva de Chile, vaciló. 
Sus excusas fueron varias. Por ejemplo, en 1615, escribió al Consejo de Indias que tenía algunas dudas sobre el valor de la historia junto con su propia capacidad de servir como cronista: «el ejercicio de él requiere no sólo letras y estudios, sino noticia i esperiencia práctica de negocios de paz i guerra i de los intentos i consejos, sospechas i malicias de los hombres». ${ }^{26}$ Aquí, Valencia se refería al debate contemporáneo dedicado a qué tipo de hombres eran los más idóneos para escribir la historia: los de letras o los de gobierno. La ironía aquí es que, algunos años antes, había escrito a un amigo humanista, el bibliotecario de el Escorial, que los hombres de letras como él tenían la responsabilidad de intervenir en los asuntos públicos.

Pero en ese momento ańadió más excusas. Aparte de la falta de experiencia directa con cosas de gobierno, expuso a los consejeros

que la escritura de la Historia requiriera muy grande actividad y diligencia para informarse de muchas personas i buscar papeles dentro i fuera del reino, y porque aviéndose de tratar la historia con la verdad i entereza que se deve, es forçoso muchas veces censurar las acciones i vidas de los príncipes y de sus ministros u otras personas grandes, reprehender i aun causar infamia a capitanes i soldados ia familias nobles, para en los siglos venidores. ${ }^{27}$

Con estos argumentos, Valencia pidió al Consejo excusarle de la historia ya empezada. Al parecer, los motivos detrás de este acto de autocensura tenían dos causas: una historiográfica y otra política, aunque interrelacionadas. Valencia elaboró su decisión de abandonar la escritura de la historia chilena en un momento cuando el debate sobre el carácter de la guerra estaba vigente. La cédula real de 1608 hizo poco por frenar a los soldados maloqueros; tácticas más parecidas a la guerra de sangre y fuego que la defensiva continuaron al punto que, en 1625, Felipe IV sancionó la primera en una nueva cédula real.

Valencia nunca declaró abiertamente su postura en el debate sobre esta guerra. Su simpatía, probablemente, se inclinaba hacía el partido

${ }^{26}$ Memoria de Pedro de Valencia, 17 de setiembre de 1616, AGI, Indiferente General, leg. 752.

${ }^{27} \mathrm{Ib}$. 
que estaba en favor de la guerra defensiva, pero también entendía que la historia, especialmente una de carácter oficial como la que él estaba encargado de escribir, lo colocaba en una posición difícil: ¡ser cronista o ser historiador? Lo primero requería mantenerse fiel a la monarquía y disimular. Lo segundo, escribir una narración verídica, algo que conllevaba ciertos riesgos, entre ellos, la posibilidad de ofender el rey y sus ministros, o como lo expresó en una carta, el peligro de «ofender a personas de calidad» y también infamar «la nación española de injusticias, avaricia i crueldades que gustarán mucho de saber los estrangeros, hereges y enemigos de esta monarquía». Aquí hacía referencia a la manera en que los holandeses y los ingleses habían utilizado la Brevísima relación de la destrucción de las Indias de Bartolomé de las Casas para fines propagandísticos. ${ }^{28}$

¿Ser historiador o cronista? Para Valencia, este fue un desafío difícil sin posibilidad de elegir entre las dos. Fue así que se inclinó por la autocensura y su decisión de excusarse de la obra, algo que hizo claro en una carta donde explicó que "poco convenía dar más noticia de aquella guerra de lo que [ya] está escrito della [...] no es materia conveniente a su instituto, ni el podrá acabar consigo e ser pregonero de culpas agenas [...]y de ningún servicio para Vuestra Majestad». ${ }^{29}$

Estas últimas palabras son importantes y también muy parecidas a unas que hubiera encontrado en los Comentarios reales, en particular en el prólogo adonde Garcilaso admitió que una de la razones que le motivaba a escribir aquella obra "fue celebrar (si no digna, al menos debidamente) las grandezas de los heroicos españoles que con su valor y ciencia militar ganaron para Dios, para su Rey y para sí, aqueste rico Imperio cuyos nombres, dignos de cedro, viven en el libro de la vida y vivirán inmortales en la memoria de los mortales». A esto, añadió que había escrito la historia "por premiar sus merecimientos con perpetua fama; por honrar su patria, cuya honra ilustre son ciudadanos y vecinos tan ilustres; y para ejemplo e imitación de la posteridad». ${ }^{30}$

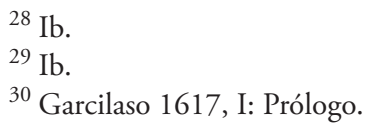


En toda conciencia, parece que Valencia, si bien dispuesto a escribir la historia de Chile, encontró difícil hacerlo porque allí debían figurar los hechos que no redundarían en honor de su patria. Finalmente, abandonó aquella historia, señalando al Consejo su interés en ocuparse en otras materias que pudieran ser de más provecho al «servicio de Dios», entre ellos, varios estudios humanísticos sobre el Nuevo Testamento, las epístolas antiguas, etc. ${ }^{31}$

La autocensura es un tema difícil de estudiar. Casi por definición, es un acto muy individual, habitualmente practicado en silencio y no suele producir mucha documentación. Por esta razón, la literatura histórica en torno al tema es mínima. Por lo tanto, es una suerte disponer tanta información pertinente a la decisión de Valencia de abandonar su historia. Varios fueron los factores que le encaminaron esta difícil decisión, pero parece que fue clave lo que había aprendido de su lectura de Garcilaso. En el presente, la literatura crítica dedicada a los Comentarios Reales es enorme, pero poco se ha dedicado a la manera en que los contemporáneos de Garcilaso leyeron y reaccionaron a la obra. De este modo, el caso de Valencia es llamativo. Como cronista encargado de censurar el texto inédito, lo leyó con el ojo dedicado a encontrar cosas que le parecían heréticas o contrarias a los intereses de la Corona española. No encontró ni lo uno ni la otro y, por lo tanto, podía recomendar al Consejo y al rey que le diesen al autor la licencia necesaria para la impresión.

Aparte de leer los Comentarios Reales en esta manera tan oficial, parece que Valencia, quien carecía de experiencia previa en la disciplina histórica, los leyó como si fuera un tratado de historiografía, una obra que pudiera ofrecerle lecciones que necesitaba para la historia de Chile que tenía en proceso. ¡Qué suerte había tenido Garcilaso! Si no hubiese sido Valencia, el único otro cronista real capaz de evaluar su historia habría sido Antonio

${ }^{31}$ Memorial de Pedro de Valencia; 17 de setiembre de 1616; AGI, Indiferente General, leg. 752 . 
de Herrera y Tordesillas, historiador prolífico, pero sin escrúpulos, que había demostrado anteriormente en varias de sus obras su capacidad de plagiar los escritos de otros. De hecho, se puede especular que si el Consejo de Indias hubiera pedido a Herrera realizar la censura de los Comentarios Reales, es probable que no hubiera recomendado conceder la licencia de impresión o hubiera dilatado mucho en recomendarla y, a la vez, incorporado mucho de lo que hubiera encontrado en el texto del tercer tomo de la Décadas, es decir, en su propia historia general de las Indias, obra todavía no acabada, y que, aparecida en 1615, tomó mucho de La Florida del Ynca de Garcilaso impresa anteriormente.

Lo que es cierto es que Garcilaso, aparte de todas sus contribuciones a la historia peruana, también era un excelente maestro, un verdadero artista de la historia, cuyos consejos para escribir una buena obra influyeron en Valencia. La ironía aquí es que al tener que enfrentar la redacción de una historia de Chile, esta no pudo ser acabada. Sin embargo, esto no disminuye en nada la importancia del Inca, un historiador, que ayer como hoy, sigue ofreciéndonos importantes lecciones de lo que consiste la buena historia y los métodos necesarios para escribirla. Le agradezco a Garcilaso en nombre de todos los miembros de nuestro gremio y también de todos los lectores de sus obras. Junto con Pedro de Valencia, todos estamos en deuda.

\section{BIBLIOGRAFÍA}

Brendecke, Arndt. 2016. Imperio e información. Funciones del saber en el dominio colonial español. Madrid: Iberoamericana-Vervuert. https://doi. org/10.31819/9783954870769

Cabrera de Córdoba, Luis. 1948. De historia, para entenderla y escribirla. Edición de Santiago Montero Díaz. Madrid: Instituto de Estudios Políticos.

Díaz Blanco, José Manuel. 2010. Razón de Estado y Buen Gobierno. La Guerra Defensiva y el imperialismo español en tiempos de Felipe III. Sevilla: Universidad de Sevilla.

Garcilaso de la Vega. 1617. Historia General de Perú. Córdoba: Viuda de Andrés Barrera. Fuente consultada en: <http://shemer.mslib.huji.ac.il/lib/W/ ebooks/001531298.pdf>

Gómez Canseco, Luis. 1993. El humanismo después de 1600: Pedro de Valencia. Sevilla: Universidad de Sevilla. 
González de Nájera, Alfonso. 1866. «Desengaño y reparo de la guerra de Chile». En Colección de Documentos Inéditos para la Historia de España. Volumen XLVIII. Madrid: Imprenta de la Viuda de Calero.

Grafton, Anthony. 2007. What Was History? The Art of History in Early Modern Europe. Cambridge: Cambridge University Press.

Jara, Álvaro. 1971. Guerra y sociedad en Chile. Santiago de Chile: Editorial Universitaria.

Kagan, Richard. 2010. Los Cronistas y la Corona. Madrid: Marcial Pons Editores. Kagan, Richard. 2017. «Ante todo, nunca te mientas a ti mismo: Pedro de Valencia, la Historia de Chile y la autocensura». Manuscrits. Revista d'història moderna. Vol. 35: 83-101. https://doi.org/10.5565/rev/manuscrits. 171

Luciano. 1959. «How to Write History». En Kilburn, K. Lucian. Vol. VI. Cambridge: Harvard University Press y Loeb Classical Library. https://doi.org/10.4159/ DLCL.lucian-how_write_history.1959

Magnier, Grace. 2010. Pedro de Valencia and the Catholic Apologists of the Expulsion of the Moriscos. Leiden: Brill. https://doi.org/10.1163/ej.9789004182882.i-434

Murúa, Fray Martín de. 1962-1964. Historia General del Perú. Edición de Manuel Ballesteros. Madrid: Gongora, 2 vols.

Paniagua Pérez, Jesús. 1996. «Pedro de Valencia, cronista e historiógrafo oficial de las Indias». Anuario de Estudios Americanos. Vol. 53, número 2: 231-249. https:// doi.org/10.3989/aeamer.1996.v53.i2.422

Polibio, 1991. Historias. Libros I-IV. Madrid: Gredos.

Porras Barrenechea, Raúl. 1955. El Inca Garcilaso en Montilla, 1561-1611. Nuevos documentos hallados y publicados. Lima: Editorial San Marcos.

Valdivia, Luis de. 1610. Tratado de la importancia del medio que el Virrey propone, de cortar la guerra de Chile y hazerlo solamente defensiva. Madrid: s.i.

Valencia, Pedro de. 2012. Epistolario. Madrid: Ediciones Clásicas.

Valencia, Pedro de. 1993-2016. Obras Completas de Pedro de Valencia. León: Universidad de León, 12 vols.

Fecha de recepción: 17/XII/2020

Fecha de aceptación: 24/II/2021 